\title{
A Novel DR/NIR T-Shaped AIEgen: Synthesis and X-Ray Crystal Structure Study
}

\author{
Rosita Diana ${ }^{1}$, Ugo Caruso ${ }^{2}{ }^{(1)}$, Luigi Di Costanzo ${ }^{1}$, Gelsomina Bakayoko ${ }^{2}$ \\ and Barbara Panunzi 1,*(D) \\ 1 Department of Agriculture, University of Napoli Federico II, 80055 Portici NA, Italy; \\ rosita.diana@unina.it (R.D.); luigi.dicostanzo4@unina.it (L.D.C.) \\ 2 Department of Chemical Sciences, University of Napoli Federico II, 80126 Napoli, Italy; \\ ugo.caruso@unina.it (U.C.); gelsominabakayoko@gmail.com (G.B.) \\ * Correspondence: barbara.panunzi@unina.it; Tel.: +39-081-674170
}

Received: 11 March 2020; Accepted: 31 March 2020; Published: 2 April 2020

\begin{abstract}
We developed a new benzodifuran derivative as the condensation product between 2,6-diamino -4-(4-nitrophenyl)benzo[1,2-b:4,5-b']difuran-3,7-dicarboxylate and 3-hydroxy-2-naphthaldehyde. The intramolecular hydrogen-bond interactions in the terminal half-salen moieties produce a sterically encumbered highly conjugated main plane and a D-A-D (donor-acceptor-donor) T-shaped structure. The novel AIEgen (aggregation-induced enhanced emission generator) fulfils the requirement of RIR (restriction of intramolecular rotation) molecules. DR/NIR (deep red/near infrared) emission was recorded in solution and in the solid state, with a noteworthy photoluminescence quantum yield recorded on the neat crystals which undergo some mechanochromism. The crystal structure study of the probe from data collected at a synchrotron X-ray source shows a main aromatic plane $\pi$-stacked in a columnar arrangement.
\end{abstract}

Keywords: DR/NIR; fluorescence; AIEgen; T-shaped

\section{Introduction}

In recent years, the design and synthesis of organic fluorescent dyes highly performant in the solid state have received researcher's widespread attention [1-4]. For some applications, the emission in neat or aggregate state is a basic requirement. This is the case in most optoelectronic devices and in fluorescent bioimaging investigation techniques [5-8]. In the organic fluorophores, traditionally consisting of extended electronic $\pi$-systems, a marked fluorescence quenching in the solid state can occur due to the strong intermolecular interactions. The $\pi-\pi$ stacking of planar polycyclic skeletons and the dipole-dipole interaction of donor-acceptor frameworks $[5,9,10]$ can induce the aggregation caused quench (ACQ) effect with a significant fluorescent intensity decrease.

Several strategies can be adopted to suppress undesired strong intermolecular interactions. The fundamental issue is designing a conjugate system depressing the non-radiative deactivation processes through restriction of intramolecular rotation (RIR), restriction of intramolecular vibrations (RIV), and restriction of intramolecular motions (RIM) [10,11]. Therefore, the introduction of sterically encumbered substituents or bulky groups $[9,12,13]$ and the construction of highly twisted skeleton [14-17] are the possible solutions. Unlike the common $\pi$-conjugated fluorogens, this kind of molecules undergo aggregation-induced enhanced emission (AIE) effect providing photoluminescence (PL) in the solid state.

Among the AIEgens (aggregation-induced enhanced emission generators) first described by Tang group in 2001 [18], a special class is represented by the DR/NIR (deep red/near-infrared) fluorophores, characterized by a strong emission at the $650-900 \mathrm{~nm}$ region [19]. According to the energy-gap 
law [20-22] the intrinsic low band-gap of such DR/NIR emitters makes them especially vulnerable to the ACQ effect [23] due to higher vibrionic coupling between the ground and excited states. Therefore, most of the AIEgens reported emit blue and green lights. Although they are highly sought after for red OLEDs (Organic Light Emitting Diodes), night-vision devices, secured displays, optical waveguides and in the wide field of bio and chemo-sensing [24-28], there are fewer efficient DR/NIR (deep red/near infrared) materials. Of particular interest are AIE fluorophores with intense emission at DR/NIR region owing to their deep tissue penetration, photo-stability and minimum interference in living systems $[25,29,30]$. Their applications are closely related to cell imaging and DNA and protein sensing [31-33].

Novel molecular construction of DR/NIR AIEgens can be achieved with electron donor (D) and electron acceptor (A) blocks connected through $\pi$-conjugated frameworks. The most fundamental phenomenon governing the spectroscopic properties is the intramolecular charge transfer (ICT) process from the donor to the acceptor in the excited state [34-36]. Intercrossed excited state between the low-lying local exciton (LE) and charge transfer (CT) exciton results from the D-A interaction. Obviously, the molecular geometry is crucial for the process.

Benzodifuran derivatives have drawn attention for a wide range of biological and pharmacological applications, including antimicrobial, antiviral, analgesic and antitumor [37-40] activity. This class of heterocyclic compounds are also employed in dyes industry as pigments and in different fields of optoelectronics and photonics. Due to the excellent semiconducting properties [41,42], benzodifuran scaffolds are used as nonlinear optical materials [43], for dye sensitized solar cells [44] and in organic solar cell and transistors. Finally, as electron-rich building blocks they have a potential in the constructing of photoluminescent materials [45-47]

Herein, we developed a new benzodifuran derivative from 2,6-diamino-4-(4-nitrophenyl) benzo[1,2-b:4,5-b']difuran-3,7-dicarboxylate [40] (BDF moiety in Scheme 1). Keeping in mind the ability of nitrophenyl ring to twist respect to $B D F$ plane in similar molecules [43], herein, we designed a new T-shaped twisted molecule. The reaction of the precursor BDF (shown in Scheme 1) with the highly fused naphthol rings of 3-hydroxy-2-naphthaldehyde produced terminal Schiff bases moieties and an extended D-A-D T-mode conjugation.

The novel AIEgen NBDF (reported in Scheme 1) fulfils the requirement of RIR molecules. We investigated its photophysical properties and correlated the data to its single crystal structure resolved from data collected at synchrotron source. 


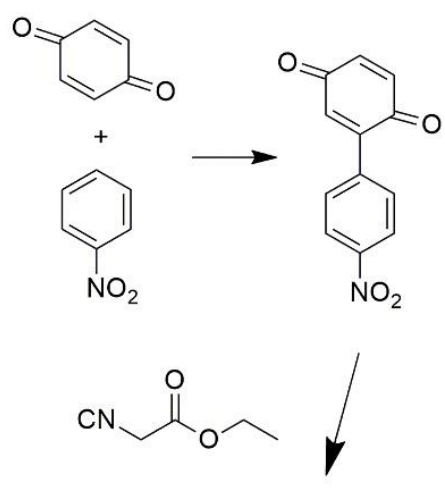<smiles>CCOC(=O)c1c(N)oc2c(-c3ccc([N+](=O)[O-])cc3)c3c(C(=O)OCC)c(N)oc3cc12</smiles>

$B D F$

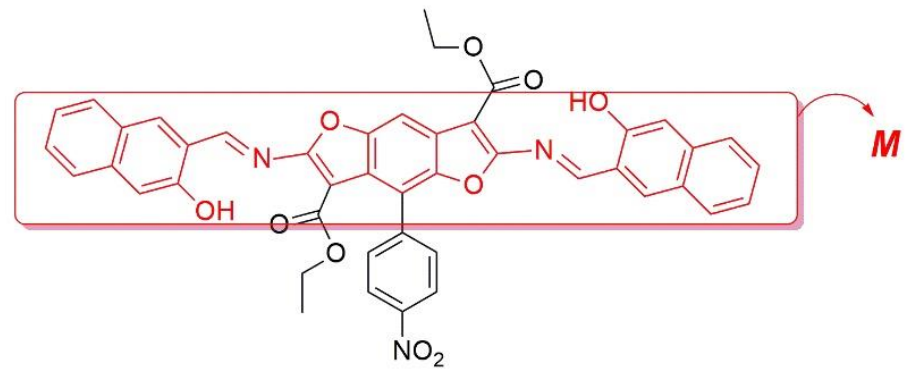

NBDF

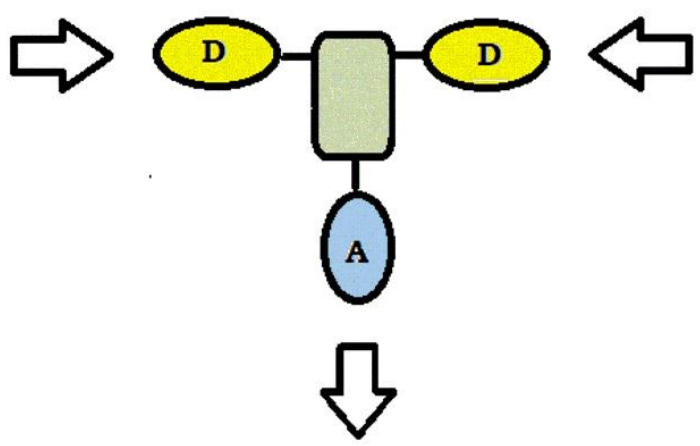

Scheme 1. Synthetic route to the target compound NBDF. D-A-D T-shaped molecule schematically represented. $M$ is the plane containing the diamino-benzodifuran rings condensed with the two 3-hydroxy-2-naphthaldehyde moieties, i.e., the fragment depicted in red.

\section{Experimental}

Commercially available starting products were supplied by Sigma Aldrich. PVK was molecular weight 1100 Da. 2,6-diamino-4-(4-nitrophenyl)benzo[1,2-b:4,5-b']difuran-3,7-dicarboxylate (BDF) was obtained as described in [48]. ${ }^{1} \mathrm{H}$ NMR spectra were recorded in 1,1,2,2-tetrachlorethane-d2 with a 
Bruker Advance II 400MHz apparatus (Bruker Corporation, Billerica, MA, USA). Mass spectrometry measurements were performed using a Q-TOF premier instrument (Waters, Milford, MA, USA) with an electrospray ion source and a hybrid quadrupole-time of flight analyzer.

Optical observations were performed by using a Zeiss Axioscop polarizing microscope (Carl Zeiss, Oberkochen, Germany) equipped with an FP90 Mettler microfurnace (Mettler-Toledo International INC MTD, Columbus, OH, USA). The decomposition temperatures ( $5 \mathrm{wt} . \%$ weight loss) and phase transition temperatures and enthalpies were measured under nitrogen flow by employ of a DSC/TGA Perkin Elmer TGA 4000 (PerkinElmer, Inc., Waltham, MA, USA), scanning rate $10^{\circ} \mathrm{C} / \mathrm{min}$. Absorption and UV-Visible emission spectra were recorded by JASCO F-530 and FP-750 spectrometers (scan rate $200 \mathrm{~nm} \mathrm{~min}{ }^{-1}$, JASCO Inc., Easton, MD, USA) and on a spectrofluorometer Jasco FP-750 (excitation wavelengths set at the absorption maxima of the samples, scan rate $125 \mathrm{~nm}$ min-1, JASCO Inc., Easton, MD, USA). Thin films of the neat samples and of the polymeric blends $(20 \% \mathrm{wt}$. in PVK, molecular weight $1100 \mathrm{Da}$ ) were prepared using a SCS P6700 spin coater operating at 600 RPM for $1 \mathrm{~min}$.

Photoluminescence quantum efficiency values were recorded on quartz substrates by a Fluorolog 3 spectrofluorometer (Horiba Jobin Instruments SA), within an integrating sphere provided by an optical fiber connection.

\subsection{Synthesis of NBDF}

To $0.453 \mathrm{~g}(1.00 \mathrm{mmol})$ of BDF dissolved at $70{ }^{\circ} \mathrm{C}$ in $20 \mathrm{~mL}$ of glacial acetic acid $0.688 \mathrm{~g}(4.00$ mmol) of 3-hydroxy-2-naphthaldehyde was added under stirring. After 1 hour at boiling temperature, the crude product precipitated. The compound was recovered from the hot solution and washed in hot ethanol twice. $\mathrm{Tm}=330{ }^{\circ} \mathrm{C}$; $\mathrm{Td}=340{ }^{\circ} \mathrm{C} .{ }^{1} \mathrm{H}$ NMR $(500 \mathrm{MHz}, 1,1,2,2$-tetrachlorethane (TCE)-d2, $\left.25^{\circ} \mathrm{C}, \mathrm{ppm}\right): 0.87(\mathrm{t}, 3 \mathrm{H}), 1.08(\mathrm{t}, 3 \mathrm{H}), 3.93(\mathrm{q}, 2 \mathrm{H}), 4.54(\mathrm{q}, 2 \mathrm{H}), 7.15(\mathrm{t}, 2 \mathrm{H}), 7.44(\mathrm{~m}, 2 \mathrm{H}), 7.63(\mathrm{~m}, 2 \mathrm{H})$, $7.74(\mathrm{~m}, 2 \mathrm{H}), 7.85(\mathrm{~d}, 2 \mathrm{H}), 7.88(\mathrm{~d}, 2 \mathrm{H}), 7.92(\mathrm{~d}, 1 \mathrm{H}), 8.18(\mathrm{~s}, 1 \mathrm{H}), 8.25(\mathrm{~s}, 1 \mathrm{H}), 8.45(\mathrm{~d}, 2 \mathrm{H}), 9.47(\mathrm{~s}, 1 \mathrm{H})$. $9.76(\mathrm{~s}, 1 \mathrm{H})$. Elemental analysis calculated $(\%)$ for $\mathrm{C}_{44} \mathrm{H}_{31} \mathrm{~N}_{3} \mathrm{O}_{10}: \mathrm{C}, 69.38 ; \mathrm{H}, 4.10 ; \mathrm{N}, 5.52$; found: $\mathrm{C}$, 69.30; H, 4.98; N, 5.58. MALDI-TOF of A1 m/z: $762.69(\mathrm{M}+\mathrm{H})$.

\subsection{X-Ray Crystallography}

Red needles of NBDF were obtained by slow evaporation ( 2-3 days) from a solution of TCE and acetic acid (1.5 $\mathrm{mM}$ of $1 \%$ solution of acetic acid). Crystals grew with morphology of long slender needles and dimensions of $0.07 \times 0.1 \times 0.6 \mathrm{~mm}$. Crystals required data to be collected with synchrotron radiation (wavelength, $\lambda=0.7000 \AA$ ) from XRD2 beamline at the Elettra Synchrotron Light Source, Trieste Italy. NBDF crystals undergoing solvent loss required quick harvesting in mother liquor. By using a small loop of fine rayon fiber, the selected crystal was dipped in the cryoprotectant Fomblin oil and flash-frozen in a stream of nitrogen at $100 \mathrm{~K}$. Several crystals were scanned in order to find the most suitable for data collection. For the best diffracting crystal, a total of 400-degree crystal rotation data were collected from two hundred images using an oscillation range of $2^{\circ}$. No crystal decay was detected. Data were processed using XDS (X-ray Detector Software) for processing single-crystal monochromatic diffraction data recorded) with the data collection statistics reported in Table $1[40,49]$. The crystal gave a primitive monoclinic cell of $a=16.41 \AA, b=4.78 \AA, c=25.89 \AA, \mathrm{b}=91.2^{\circ}, V=2030 \AA^{3}$ and $P \quad 121 / \mathrm{m} 1$ symmetry was confirmed by Laue group analysis from unmerged intensity using POINTLESS 1.11.21 [50] and no data twinning was detected. Data diffraction resembles that of a tiny protein crystal as only the most intense reflections could be collected, especially at low resolution $($ Rmerge $=0.070)$. Despite data completeness being only $77 \%(\mathrm{I} / \sigma(\mathrm{I})=2.3)$ at resolution of $0.93 \AA$ structure solution was quickly found by direct methods using SIR2019 [51] and revealed most of the expected NBDF atoms connectivity. The structure solution by direct methods was possible in the space groups $P 12_{1} 1, P 12_{1} / \mathrm{n} 1$ or $P 1 \mathrm{n} 1$ and revealed an equivalent and unique solution. Final refinement was performed in centrosymmetric space group $P 12_{1} / \mathrm{n} 1$ in order to achieve better refinement statistics and better ratio of refinement parameters versus number of unique reflections. Structure was anisotropically refined by using full matrix least-squares methods on $\mathrm{F}^{2}$ against all independent 
measured reflections using SHELXL [52] run under WinGX suite for small molecule single crystal [53]. All the hydrogen atoms were introduced in calculated positions and refined in agreement with a riding model as implemented in SHELXL. Restraints were introduced at last stage of refinement using FRAG, DFIX, and SIMU instructions as implemented in SHELXL [54]. Nitrophenyl group, ester groups and TCE solvent are disordered and refined as mutually exclusive by introducing free variables as implemented in SHELXL. Thermal motion of disordered solvent and the nitro-phenyl group results in somehow high values of refinement parameters (see Table 1). The figures were generated using Mercury CSD 3.6 [55]. Crystallographic data for NDBF were deposited with the Cambridge Crystallographic Data Centre and can be obtained via https:/www.ccdc.cam.ac.uk/structures/.

Table 1. Crystal data and structure refinement details for NBDF.

\begin{tabular}{|c|c|}
\hline & $N B D F$ \\
\hline CCDC number & 1988060 \\
\hline Formula probe and solvent & $\mathrm{C}_{44} \mathrm{H}_{31} \mathrm{~N}_{3} \mathrm{O}_{10} \cdot \mathrm{C}_{2} \mathrm{H}_{2} \mathrm{Cl}_{4}$ \\
\hline Temperature (K) & 100 \\
\hline Wavelength $(\AA)$ & 0.7000 \\
\hline Crystal system & Monoclinic \\
\hline Space group & $P 121 / \mathrm{n} 1$ \\
\hline$a(\AA)$ & $16.413(6)$ \\
\hline$b(\AA)$ & $4.779(1)$ \\
\hline$c(\AA)$ & $25.891(4)$ \\
\hline$\beta\left({ }^{\circ}\right)$ & $91.172(11)$ \\
\hline R-merge (last shell: $0.87-0.82 \AA$ ) & $0.070(0.559)$ \\
\hline $\mathrm{CC}(1 / 2)$ & $0.998(0.895)$ \\
\hline $\mathrm{I} / \sigma(\mathrm{I})$ & $8.4(1.3)$ \\
\hline Completeness (\%) & 71.9 \\
\hline Estimated mosaicity $\left({ }^{\circ}\right)$ & 0.25 \\
\hline Volume & $2030.4 \AA^{3}$ \\
\hline Z & 2 \\
\hline Calculated density & $1.519 \mathrm{~g} / \mathrm{cm}^{3}$ \\
\hline$\theta$ range for data collection $\left(^{\circ}\right)$ & 1.550 to 25.397 \\
\hline Reflections collected / unique & $18565 / 2855$ \\
\hline$R$ (int) & 0.0643 \\
\hline Data / restraints / parameters & $2855 / 70 / 381$ \\
\hline$R 1$ indices $(\mathrm{I}>2 \sigma(\mathrm{I}), 1913)$ & $0.1275(0.1538$, all data $)$ \\
\hline$w R 2$ & $0.345(0.371$, all data $)$ \\
\hline$F(000)$ & 922 \\
\hline Largest diff. peak and hole & 0.82 and $-0.38 \mathrm{e}-/ \AA^{3}$ \\
\hline Goodness-of-fit on $\mathrm{F}^{2}$ & 1.53 \\
\hline
\end{tabular}

\section{Results and Discussion}

The synthetic route for the benzodifuran precursor BDF (in Scheme 1) followed a reported procedure [40] consisting in the diazotization of 4-nitroaniline and the coupling of the diazonium salt on benzoquinone. By appropriate choice of the substituted cyanoacetate reacting with 
4'-nitro-[1,1'-biphenyl]-2,5-dione [40] a wide range of substituted benzodifuran derivatives could be obtained. In our case, after some preliminary tests, the acetyl substituents were chosen as a good compromise between solubility and ability to crystallization. Different reaction conditions were experimented by varying $B D F / 3$-hydroxy-2-naphthaldehyde ratio, the solvent and the operating temperature. The better results were obtained by using four times the stoichiometric amount of the aldehyde in boiling acetic acid. The product was recovered as microcrystalline powder directly from the hot solution with $30 \%$ yield, pure enough for the further characterization. Very selectively, the mono reacted products remain in the mother liquors.

A T-shaped molecule (see Scheme 1) can be envisioned as a cruciform structure obtained by assembling the branches to a central core determining the geometry and the extent of the electronic pattern [56].

Compound NBDF is the condensation product between a diamine and a salicylic aldehyde in 1:2 ratio. The probe contains two half-salen [12,57-59] Schiff base sites working as electron-donor arms and an electron-acceptor core. As shown in Scheme 1, the (4-nitrophenyl) benzodifuran unit represents the acceptor moiety due to the strong electron-withdrawing properties of the nitro substituent. To narrow the bandgap achieving red emission the donor naphthol aromatic cores are fused to BDF enlarging the conjugated length and enriching the aromatic pattern [24]. As a result, a highly conjugated main plane ( $M$ moiety, in Scheme 1 ) is produced in the dye.

The intramolecular hydrogen-bond interactions in the half-salen moieties cause the excited-state intramolecular proton-transfer (ESIPT) $[60,61]$ known to lead to emission in solution $[46,59,61-66]$. The same effect is known to occur in the solid state $[12,67]$ if the intramolecular H-bond produce hindrance to the torsion of sterically encumbered parts of the molecule $[57,68,69]$. In our case, the acetyl substituents on the furan rings and the bulky naphthol moieties make NBDF a RIR probe. Interestingly, RIR effect has been confirmed effective both in the solid state and in solution, as discussed below.

Identification and purity degree evaluation were assessed by elemental analysis, mass spectrometry and ${ }^{1} \mathrm{H}$ NMR (see Figure 1). The NMR pattern appears peculiar (spectrum reported in Section 2.1). The rigid H-bonded $M$ plane (in red in Scheme 1) of NBDF probe impedes rotation around single bonds also in solution. Two non-equivalent sides of the molecule are recognizable: part $a$, more encumbered due to the nitrophenyl on the same side of the acetyl group, and part $\boldsymbol{b}$ (respectively in red and in blue in Figure 1). Because of this, most resonances split. The signals of two protons at 9.47 and 9.76 ppm (same integration) can be attributed to the imine in the side $\boldsymbol{b}$ and in the side $\boldsymbol{a}$, respectively. The non-equivalent $\mathrm{OCH}_{2}$ protons appear as two quadruplets at 3.93 and $4.54 \mathrm{~nm}$ and the terminal methyl groups as two triplets at 0.87 and $1.08 \mathrm{ppm}$. In the complicated aromatic pattern couples of protons of the same naphtholic ring are equivalent (integrating for 2 protons) while the signals in the part $\boldsymbol{a}$ differ from those in the side $\boldsymbol{b}$. The three signals integrating for one proton can be attributed to the single proton on the $B D F$ unit and the two protons in the nitrophenyl ring in orto to $B D F$. In the $p$-substituted system, the two protons in orto to nitro group are recorded as one doublet at $8.45 \mathrm{ppm}$. 


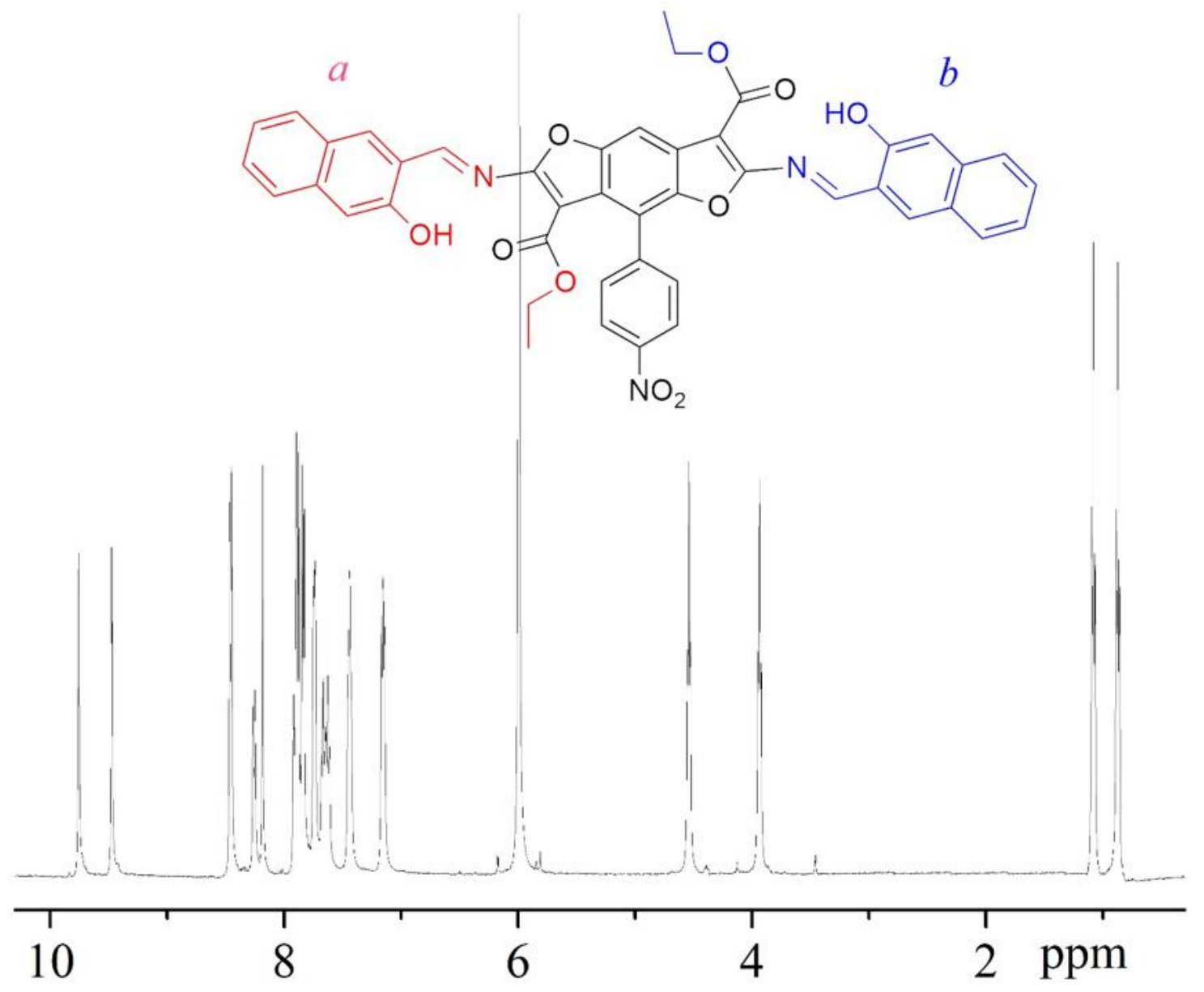

Figure 1. ${ }^{1} \mathrm{H}$ NMR of NBDF in 1,1,2,2-tetrachlorethane $\mathrm{d} 2$.

Concerning the phase behaviour, bright red crystals of $N B D F$ were obtained by slow evaporation of TCE/acetic acid solution at room temperature. Crystals appeared in $\sim 2-3$ days from a $1.5 \mathrm{mM}$ of $1 \%$ solution of acetic acid and grew with dimensions of $0.07 \times 0.1 \times 0.6 \mathrm{~mm}$. They were examined by optical observation and DSC/TGA analysis. The compound melts at $330^{\circ} \mathrm{C}$ and is thermally stable up to $350^{\circ} \mathrm{C}$ under nitrogen flow. The dye is soluble in many organic solvents. In an acid environment the solutions are stable and retain their spectroscopic characteristics up to three months under natural light at room temperature.

\subsection{Spectroscopic Behavior}

The compound underwent a spectroscopic analysis by absorption and UV-Visible emission spectrophotometry in TCE solutions and on thin films of finely crumbled spin-coated crystals.

As a pigment, $N B D F$ is red chromophore with (Commission Internationale de l'Eclairage coordinates) CIE: $(0.48 ; 0.30)$ in the solid state, $(0.58 ; 0.33)$ in TCE solution and molar extinction coefficients of 46,000 .

In solution, the absorbance pattern reveals a broad band peaked at 505 with a shoulder at 543 $\mathrm{nm}$. The emission spectrum of the same sample irradiated at the absorbance maximum shows a double peaked band (at 575 and $615 \mathrm{~nm}$, as shown in Figure 2) and $70 \mathrm{~nm}$ Stokes shift. PLQY (photoluminescence quantum yield) measured in diluted TCE solution was $2 \%$.

In the solid state, the absorbance of NBDF sample is peaked at $488 \mathrm{~nm}$. As an AIEgen its PL performance in the solid state is intriguing because the compound shows a large part of the emission band in DR region (the peak at $655 \mathrm{~nm}$, see Figure 2) and an appreciable part in the NIR region (the 
hump above $700 \mathrm{~nm}$ ). PLQY measured on the crystalline thin layer was $18 \%$, considered a good result for a DR/NIR emitter in the solid state [19].

A large Stokes shift was measured in this case $(167 \mathrm{~nm}$ from the maximum of absorbance, used as excitation wavelength, to the first emission maximum). The intramolecular relaxation process from $\mathrm{LE}$ state to the ICT state usually leads to a large Stokes shift [70]. The reabsorption of the emitted photons is avoided in fluorophores with large Stokes shift making them highly efficient. Emission spectra of NBDF both in TCE solution and in the crystalline phase are showed in Figure 2.

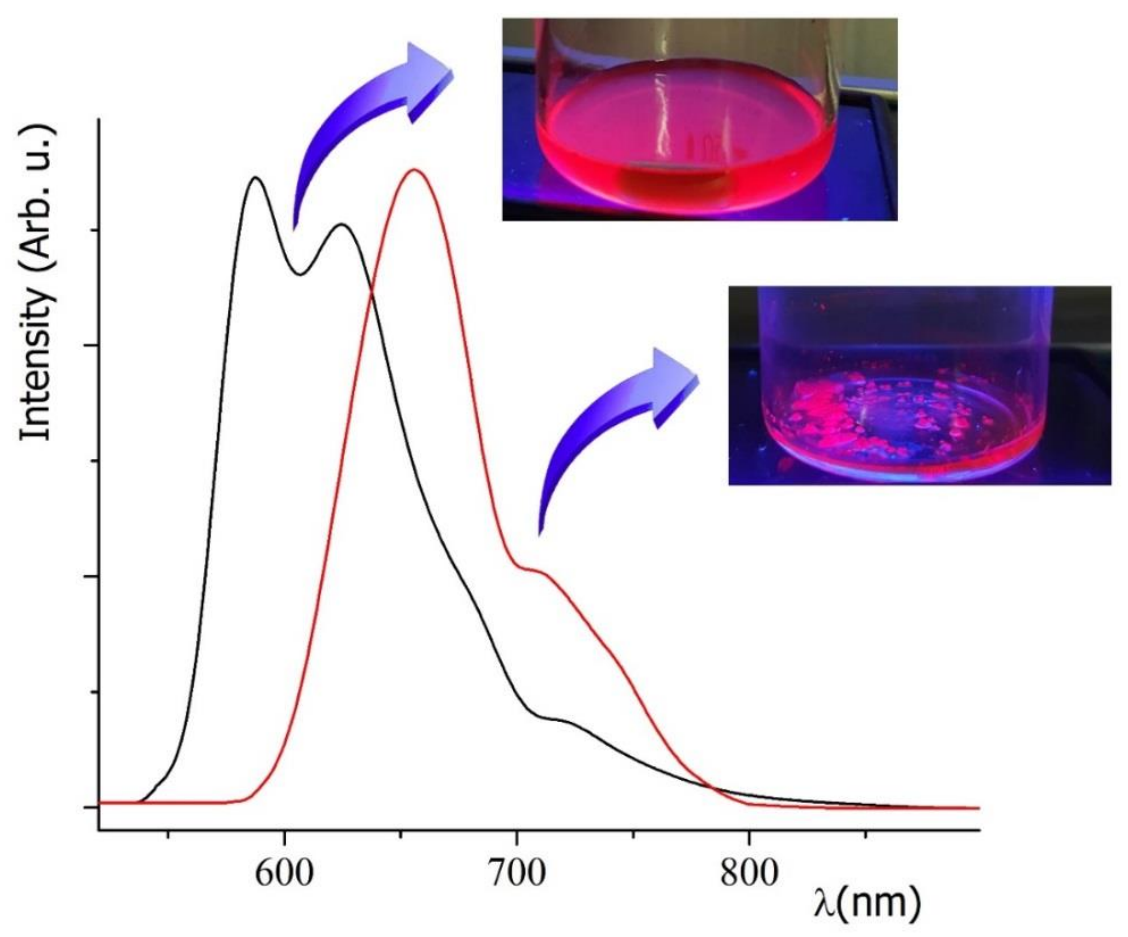

Figure 2. Emission spectra of NBDF in TCE (black curve) and in the solid phase (red curve). In the insets, the same samples employed for the spectroscopic characterization.

On solutions of NBDF probe was observed the typical behaviour of AIEgens, depending on a different solvent/non-solvent ratio. The emission performance was examined in TCE/hexane. In diluted TCE solutions $(0.2 \mathrm{mM})$ the sample displays poor red emission. Upon incremental addition of hexane to the TCE sample, red fluorescence increases, as can be naked-eye perceived, starting from $60 \%$ hexane solution (see Figure $3 \mathrm{~A}$ ). After $80 \%$ the sample undergoes precipitation. As expected for AIE undergoing molecules, the aggregation process involving the self-assembly of emissive units improve fluorescence. Hydrogen bonding and van der Waals interactions are involved in the process [71].

Finally, it was found that NBDF probe produced some mechanochromic effect. The luminescence properties of compounds able to form strong stacked molecular organization are subject to the molecular packing in the solid state [72,73]. Increase in the crystallite size distribution was expected to produce higher PL intensity because of the stacking of the NBDF moieties hinders non-radiative relaxation pathways. Grinding the very fine powder of the as-synthetized compound some particles fused. The increase in the particle size distribution causes enhanced florescence intensity in NBDF. After grinding (see Figure 3B), the sample shows the same emission color with slight PL increase (about 15\%). In the fuming process, the same sample was treated with acetone vapor. We checked several solvents and the most relevant effect was found in acetone. The fumed samples were obtained by fuming the grinded powders for $1 \mathrm{~min}$. Finally, the same sample was kept at $150{ }^{\circ} \mathrm{C}$ for $3 \mathrm{~min}$ (heating process). Due to the disruption of the molecular packing obtained by grinding and the production of an amount of less structured material, PL performance are expected worsen as a result of the fuming (first) and of 
the heating (subsequent) process. In fact, the luminescent states checked by PL measurements show a small decrease correspondent to $4 \%-5 \%$ in PL intensity to each of the two stages.

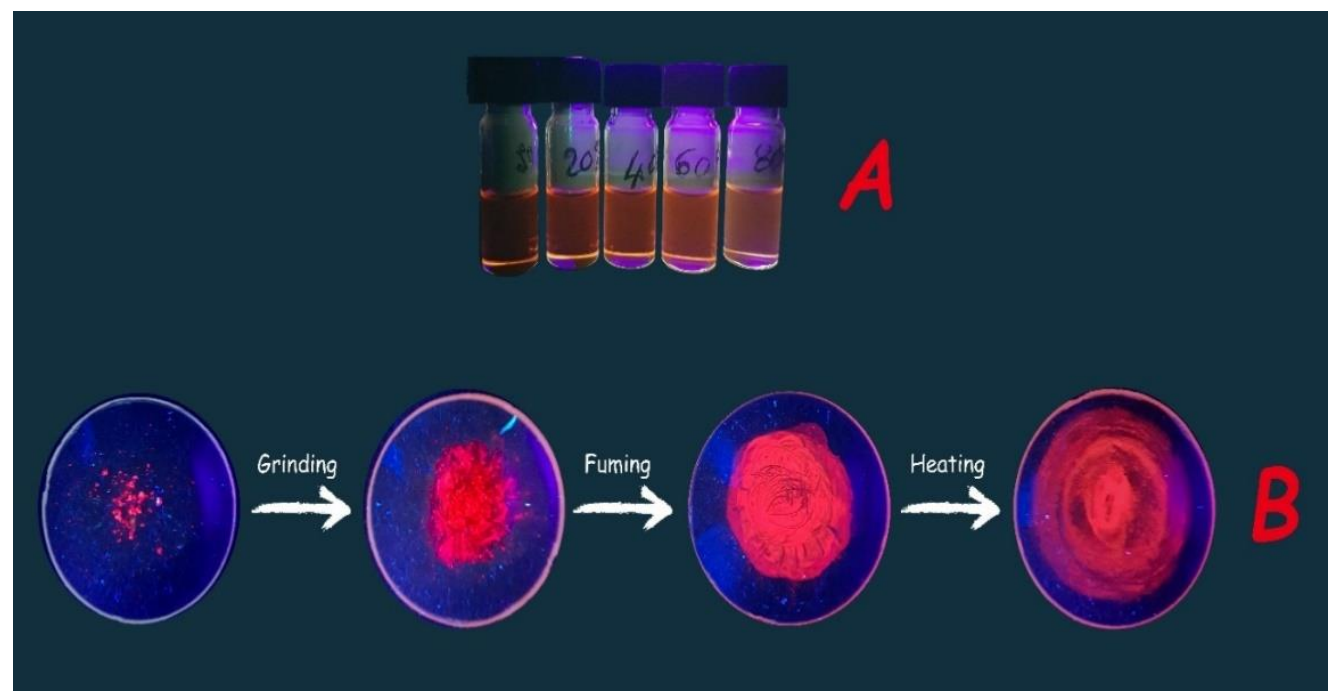

Figure 3. Above (A): Emission (under $365 \mathrm{~nm} \mathrm{UV-vis} \mathrm{lamp)} \mathrm{of} \mathrm{NBDF} \mathrm{TCE/hexane} \mathrm{solutions} \mathrm{upon}$ incremental addition of hexane to the TCE sample $(0 \%, 20 \%, 40 \%, 60 \%$ and $80 \%$, respectively). Below (B): A sample of as-synthetized NBDF (first petri dish), photographed after grinding, fuming and heating process (second, third and fourth sample, respectively).

\subsection{Production of a Red Emissive Polymeric Layer}

To further explore the potential applications of NBDF probe in the production of emissive layers, the fluorophore was mixed with poly(vinylcarbazole) (PVK), a polymeric conductive matrix often employed in optoelectronic devices. Production of polymeric blends, and more generally deposition of low-weight molecules on conductive substrates $[45,57,74]$, is a functional approach to produce macroscopically processable layers. For ACQ undergoing molecules this is a way to relieve fluorescence quenching effect $[45,57]$. In our case, the AIE performance of the dye required the employ of a high percentage of $N B D F$ in the amorphous host matrix.

Thin films of NBDF were obtained by the spin-coating of a dispersion of finely shattered crystals (obtained by sonication of a dispersion in hexane) and PVK in chloroform/hexane (3:1) using an SCS P6700 spin-coater operating at $600 \mathrm{rpm}$. All the blends produced homogeneous microcrystalline layers retaining their optical characteristics up to two months under natural light at room temperature.

Up to $5 \%$ wt. the addition of PVK acted as a conductive plasticizer, with no relevant decrease of PLQY. In the larger host percentage blends, from $5 \%$ to $25 \%$ wt., PLQYs rapidly decreased to about one half ( $8 \%$ PLQY was recorded on the more diluted sample). Not unexpected, both in solid and in liquid diluted media the emission of the AIEgen weakens. The emission color of the neat compound placed in the DR region with CIE: $(0.68 ; 0.32)$, see Figure 4 . On the other hand, going from the neat crystalline dye ( $0 \%$ PVK blend) up to $25 \%$ PVK blend the CIE coordinates gradually undergo blue-shift, so that emission color of $25 \%$ blend is very similar to the $30 \%$ wt. TCE solution, CIE: $(0.58 ; 0.43)$ and $(0.58$; 0.42 ) respectively (Figure 4). 


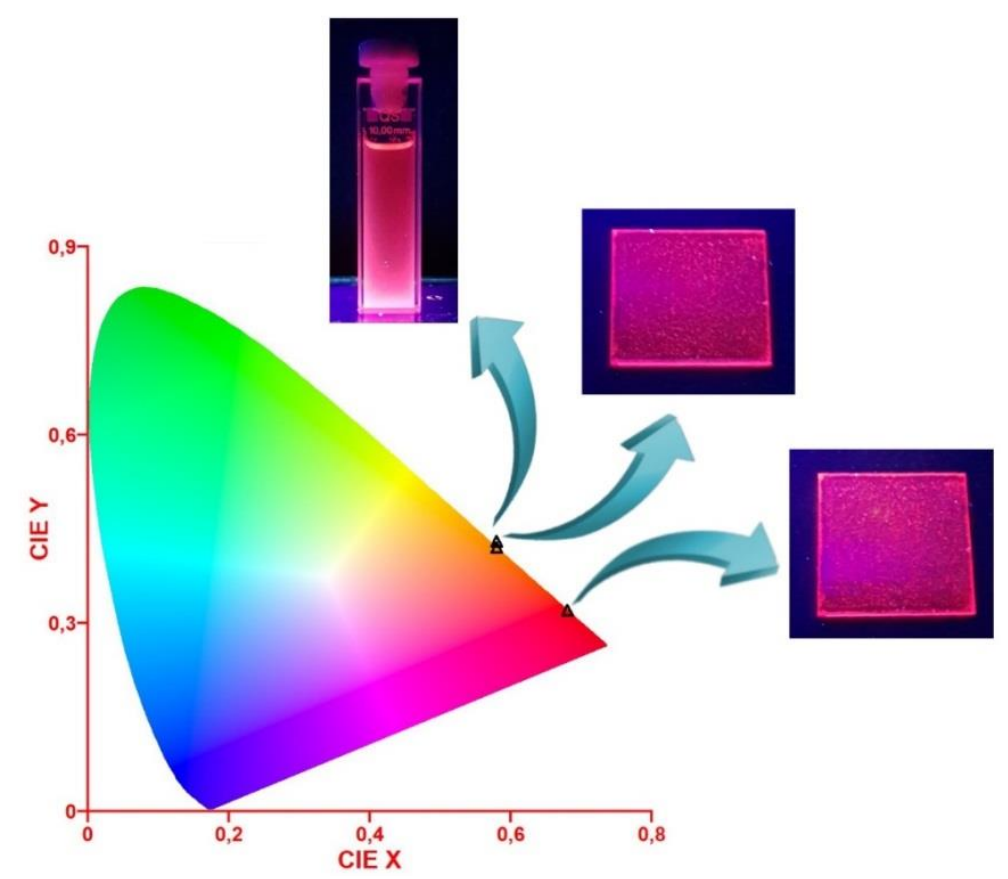

Figure 4. CIE emission diagram of NBDF and of its 30\% wt. TCE solution and 25\% wt. PVK blend (overlapped). The samples used for CIE calculation in the insets.

\subsection{Single-Crystal X-Ray Structure}

The molecular structure of NBDF shows a T-shaped pattern recognizable in the two different segments: main plane ( $M$ in red in Scheme 1 ) and nitrophenyl group (Figure 5). The probe crystallizes in $P 121 / n 1$ space group with one molecule in the asymmetric unit, as a combination of two $50 \%$ statistically equivalent molecules oriented in opposite directions. A partially occupied molecule of TCE was also detected (Figure 5). The center of symmetry of $P 12_{1} / n 1$ space group is located in the center of the benzene ring of $B D F$. NBDF shows a main plane corresponding to the $B D F$ core condensed with the two naphthol units, with an average displacement of the atoms of about $\sim 0.03 \AA$. NBDF shows an intramolecular N--H-O hydrogen bond in the half-salen group $(\mathrm{O} \ldots \mathrm{N}$ distance $=2.55 \AA$ ) enforcing the planarity of the system. The disordered nitro-phenyl group is twisted of $\sim 45^{\circ}$ with respect to the main plane, to minimize interactions with the close bulky disordered ethyl-ester group, also out from the main plane. In turn, ethyl-ester group twisted of $\sim 28^{\circ}$ with respect to the main plane. This pattern was already observed in $B D F$ molecules [45]. The strictly hindered rotations satisfy the requirements of RIR molecules.

A crystal packing with herringbone arrangement of NBDF molecules can be observed (see Figure 6). $N B D F$ is stabilized by intermolecular Van-der Waals interactions and self-assembled into $\pi$-stacked columns along the $\mathbf{b}$ axis and arranged around the center of symmetry and the symmetry elements of the space group (Figure 6). Each columnar arrangement is characterized by strong $\pi-\pi$ interactions along the main plane and by an average interplanar distance of $\sim 3.5 \AA$ (Figure 6 ). 

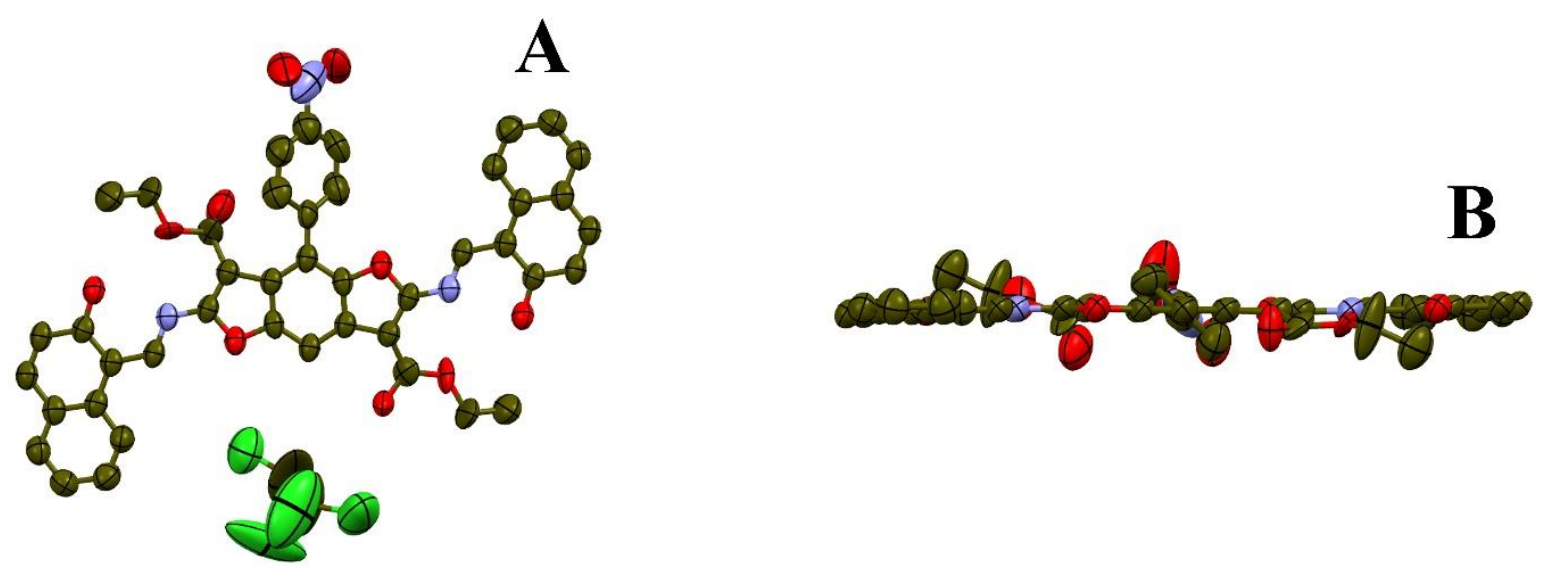

Figure 5. A: molecular structure of $\mathrm{NBDF} \mathrm{C}_{2} \mathrm{H}_{2} \mathrm{Cl}_{4}$. Thermal ellipsoids representation of atoms is drawn at $25 \%$ probability level. The center of the benzene ring of BDF is located on the center of symmetry of $\mathrm{P} 21 / \mathrm{n}$ space group. Only one orientation of the molecule is shown for clarity. B: orthogonal view showing NBDF flat structure of the main plane and deviation from planarity of nitrophenyl group and ester groups.
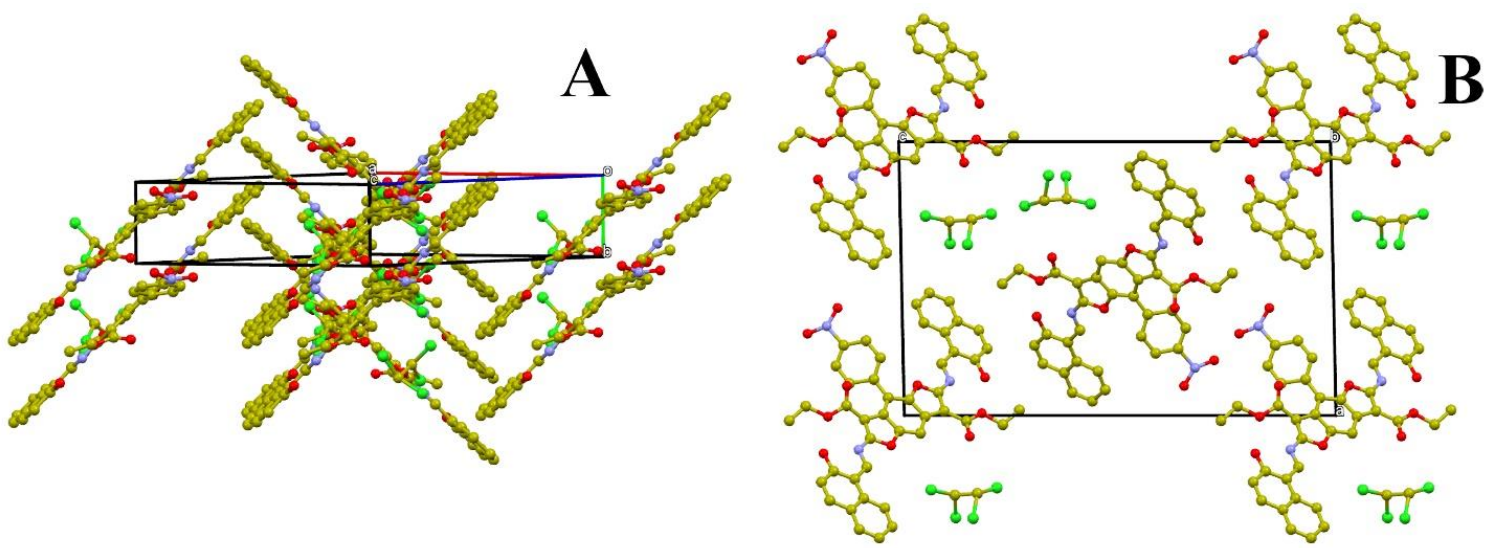

Figure 6. A: crystal packing forming a columnar arrangement of $\pi$-stacked NBDF molecules. B: crystal packing along $\mathbf{b}$ axis direction.

\section{Conclusions}

We examined the PL performance of a novel AIEgen. The central BDF scaffold forms a single main plane with two half-salen terminal naphthol groups. The probe shows a T-shaped D-A-D pattern highly encumbered, undergoing RIR effect both in solution and in the solid state. Crystal structure analysis revealed a strong intramolecular $\mathrm{H}$-bond and the ability to form $\pi$-stacked columns. The emission pattern of the neat compound is placed in the DR/NIR region with noteworthy PLQY in the solid state. The neat crystals undergo mechanochromism depending on the crystallite size distribution. In solution, NBDF keeps the typical behaviour of AIEgens compliant with the self-assembly of emissive units. Finally, the probe turned out to be potentially useful in building concentered dye-doped emissive layers. Emission CIE coordinates $(0.68 ; 0.32)$ place the probe in the highly sought-after groups of solid-state DR fluorophores.

Author Contributions: Conceptualization, R.D.; Data curation, R.D. and U.C.; Formal analysis, L.D.C.; Funding acquisition, B.P.; Investigation, R.D. and G.B.; Methodology, U.C.; Project administration, B.P.; Software, U.C.; Supervision, B.P; Validation, R.D.; Writing-original draft, R.D., L.D.C.; Writing-review and editing, B.P. All authors have read and agreed to the published version of the manuscript.

Funding: We gratefully acknowledge the financial aid provided by the Italian Ministry of Education, University and Research (MIUR) under grants PON PANDION 01_00375. 
Acknowledgments: We thank the Elettra Synchrotron (Trieste, Italy), beamline scientists Annie Heroux and Nicola Demitri for assistance with data collection, Silvano Geremia for insightful comments on structure refinement and Angela Tuzi for the useful discussion about structural section.

Conflicts of Interest: There are no conflict to declare.

\section{References}

1. Li, W.; Pan, Y.; Xiao, R.; Peng, Q.; Zhang, S.; Ma, D.; Li, F.; Shen, F.; Wang, Y.; Yang, B.; et al. Employing $\sim 100 \%$ Excitons in OLEDs by Utilizing a Fluorescent Molecule with Hybridized Local and Charge-Transfer Excited State. Adv. Funct. Mater. 2014, 24, 1609-1614. [CrossRef]

2. Wang, S.; Yan, X.; Cheng, Z.; Zhang, H.; Liu, Y.; Wang, Y. Highly Efficient Near-Infrared Delayed Fluorescence Organic Light Emitting Diodes Using a Phenanthrene-Based Charge-Transfer Compound. Angew. Chem. 2015, 54, 13068-13072. [CrossRef] [PubMed]

3. Yao, L.; Zhang, S.; Wang, R.; Li, W.; Shen, F.; Yang, B.; Ma, Y. Highly efficient near-infrared organic light-emitting diode based on a butterfly-shaped donor-acceptor chromophore with strong solid-state fluorescence and a large proportion of radiative excitons. Angew. Chem. 2014, 53, 2119-2123. [CrossRef] [PubMed]

4. Zhang, Y.; Wang, Y.; Song, J.; Qu, J.; Li, B.; Zhu, W.; Wong, W.-Y. Near-Infrared Emitting Materials: Near-Infrared Emitting Materials via Harvesting Triplet Excitons: Molecular Design, Properties, and Application in Organic Light Emitting Diodes (Advanced Optical Materials 18/2018). Adv. Opt. Mater. 2018, 6, 1870070. [CrossRef]

5. Anthony, S.P. Organic Solid-State Fluorescence: Strategies for Generating Switchable and Tunable Fluorescent Materials. ChemPlusChem 2012, 77, 518-531. [CrossRef]

6. Kwok, R.T.; Leung, C.W.; Lam, J.W.; Tang, B.Z. Biosensing by luminogens with aggregation-induced emission characteristics. Chem. Soc. Rev. 2015, 44, 4228-4238. [CrossRef]

7. Li, K.; Liu, Y.; Li, Y.; Feng, Q.; Hou, H.; Tang, B.Z. 2,5-bis(4-alkoxycarbonylphenyl)-1,4-diaryl-1,4dihydropyrrolo[3,2-b]pyrrole (AAPP) AIEgens: Tunable RIR and TICT characteristics and their multifunctional applications. Chem. Sci. 2017, 8, 7258-7267. [CrossRef]

8. Lu, H.; Zheng, Y.; Zhao, X.; Wang, L.; Ma, S.; Han, X.; Xu, B.; Tian, W.; Gao, H. Highly Efficient Far Red/Near-Infrared Solid Fluorophores: Aggregation-Induced Emission, Intramolecular Charge Transfer, Twisted Molecular Conformation, and Bioimaging Applications. Angew. Chem. 2016, 55, 155-159. [CrossRef]

9. Borbone, F.; Carella, A.; Caruso, U.; Roviello, G.; Tuzi, A.; Dardano, P.; Lettieri, S.; Maddalena, P.; Barsella, A. Large second-order NLO activity in poly(4-vinylpyridine) grafted with PdII and CuII chromophoric complexes with tridentate bent ligands containing heterocycles. Eur. J. Inorg. Chem. 2008, 1846-1853. [CrossRef]

10. Hong, Y.; Lam, J.W.; Tang, B.Z. Aggregation-induced emission. Chem. Soc. Rev. 2011, 40, 5361-5388. [CrossRef] [PubMed]

11. Mei, J.; Leung, N.L.; Kwok, R.T.; Lam, J.W.; Tang, B.Z. Aggregation-Induced Emission: Together We Shine, United We Soar! Chem. Rev. 2015, 115, 11718-11940. [CrossRef] [PubMed]

12. Diana, R.; Panunzi, B.; Concilio, S.; Marrafino, F.; Shikler, R.; Caruso, T.; Caruso, U. The Effect of Bulky Substituents on Two $\pi$-Conjugated Mesogenic Fluorophores. Their Organic Polymers and Zinc-Bridged Luminescent Networks. Polymers 2019, 11, 1379. [CrossRef] [PubMed]

13. Diana, R.; Panunzi, B.; Piotto, S.; Caruso, T.; Caruso, U. Solid-state fluorescence of two zinc coordination polymers from bulky dicyano-phenylenevinylene and bis-azobenzene cores. Inorg. Chem. Commun. 2019, 110, 107602. [CrossRef]

14. Iida, A.; Yamaguchi, S. Intense solid-state blue emission with a small Stokes' shift: Pi-stacking protection of the diphenylanthracene skeleton. Chem. Commun. 2009, 3002-3004. [CrossRef] [PubMed]

15. Zhao, Z.; Chen, S.; Lam, J.W.; Lu, P.; Zhong, Y.; Wong, K.S.; Kwok, H.S.; Tang, B.Z. Creation of highly efficient solid emitter by decorating pyrene core with AIE-active tetraphenylethene peripheries. Chem. Commun. 2010, 46, 2221-2223. [CrossRef]

16. Jiménez, Á.J.; Lin, M.-J.; Burschka, C.; Becker, J.; Settels, V.; Engels, B.; Würthner, F. Structure-property relationships for 1,7-diphenoxy-perylene bisimides in solution and in the solid state. Chem. Sci. 2014, 5, 608-619. [CrossRef] 
17. Shimizu, M.; Fukui, H.; Natakani, M.; Sakaguchi, H. Aggregation-Induced Orange-to-Red Fluorescence of 2,5-Bis(diarylamino)terephthalic Acid Dithioesters. Eur. J. Org. Chem. 2016, 2016, 5950-5956. [CrossRef]

18. Luo, J.; Xie, Z.; Lam, J.W.; Cheng, L.; Chen, H.; Qiu, C.; Kwok, H.S.; Zhan, X.; Liu, Y.; Zhu, D.; et al. Aggregation-induced emission of 1-methyl-1,2,3,4,5-pentaphenylsilole. Chem. Commun. 2001, 1740-1741. [CrossRef]

19. Wan, Q.; Tong, J.; Zhang, B.; Li, Y.; Wang, Z.; Tang, B.Z. Exploration of High Efficiency AIE-Active Deep/Near-Infrared Red Emitters in OLEDs with High-Radiance. Adv. Opt. Mater. 2019, 8, 1901520. [CrossRef]

20. Englman, R.; Jortner, J. The energy gap law for radiationless transitions in large molecules. Mol. Phys. 1970, 18, 145-164. [CrossRef]

21. Bixon, M.; Jortner, J.; Cortes, J.; Heitele, H.; Michel-Beyerle, M.E. Energy Gap Law for Nonradiative and Radiative Charge Transfer in Isolated and in Solvated Supermolecules. J. Phys.Chem. 1994, 98, 7289-7299. [CrossRef]

22. Burshtein, A.I.; Krissinel, E. Free Energy Gap Law under Diffusion Control. J. Phys.Chem. 1996, 100, 3005-3015. [CrossRef]

23. Yang, W.; Liu, C.; Gao, Q.; Du, J.; Shen, P.; Liu, Y.; Yang, C. A morphology and size-dependent ON-OFF switchable NIR-emitting naphthothiazolium cyanine dye: AIE-active CIEE effect. Opt. Mater. 2017, 66, 623-629. [CrossRef]

24. Guo, Z.H.; Lei, T.; Jin, Z.X.; Wang, J.Y.; Pei, J. T-shaped donor-acceptor molecules for low-loss red-emission optical waveguide. Org. Lett. 2013, 15, 3530-3533. [CrossRef]

25. Guo, Z.; Park, S.; Yoon, J.; Shin, I. Recent progress in the development of near-infrared fluorescent probes for bioimaging applications. Chem. Soc. Rev. 2014, 43, 16-29. [CrossRef] [PubMed]

26. Zhen, S.; Wang, S.; Li, S.; Luo, W.; Gao, M.; Ng, L.G.; Goh, C.C.; Qin, A.; Zhao, Z.; Liu, B.; et al. Efficient Red/Near-Infrared Fluorophores Based on Benzo[1,2-b:4,5-b']dithiophene 1,1,5,5-Tetraoxide for Targeted Photodynamic Therapy and In Vivo Two-Photon Fluorescence Bioimaging. Adv. Funct. Mater. 2018, 28, 1706945. [CrossRef]

27. Green, O.; Gnaim, S.; Blau, R.; Eldar-Boock, A.; Satchi-Fainaro, R.; Shabat, D. Near-Infrared Dioxetane Luminophores with Direct Chemiluminescence Emission Mode. J. Am. Chem. Soc. 2017, 139, 13243-13248. [CrossRef] [PubMed]

28. Qin, W.; Ding, D.; Liu, J.; Yuan, W.Z.; Hu, Y.; Liu, B.; Tang, B.Z. Biocompatible Nanoparticles with Aggregation-Induced Emission Characteristics as Far-Red/Near-Infrared Fluorescent Bioprobes for In Vitro and In Vivo Imaging Applications. Adv. Funct. Mater. 2012, 22, 771-779. [CrossRef]

29. Qian, J.; Tang, B.Z. AIE Luminogens for Bioimaging and Theranostics: From Organelles to Animals. Chem 2017, 3, 56-91. [CrossRef]

30. Yang, Q.; Ma, Z.; Wang, H.; Zhou, B.; Zhu, S.; Zhong, Y.; Wang, J.; Wan, H.; Antaris, A.; Ma, R.; et al. Rational Design of Molecular Fluorophores for Biological Imaging in the NIR-II Window. Adv. Mater. 2017, 29. [CrossRef]

31. Han, X.; Bai, Q.; Yao, L.; Liu, H.; Gao, Y.; Li, J.; Liu, L.; Liu, Y.; Li, X.; Lu, P.; et al. Highly Efficient Solid-State Near-Infrared Emitting Material Based on Triphenylamine and Diphenylfumaronitrile with an EQE of $2.58 \%$ in Nondoped Organic Light-Emitting Diode. Adv. Funct. Mater. 2015, 25, 7521-7529. [CrossRef]

32. Zhang, Y.; Zhang, D.; Cai, M.; Li, Y.; Zhang, D.; Qiu, Y.; Duan, L. Towards highly efficient red thermally activated delayed fluorescence materials by the control of intra-molecular pi-pi stacking interactions. Nanotechnology 2016, 27, 094001. [CrossRef] [PubMed]

33. Porzio, W.; Destri, S.; Giovanella, U.; Pasini, M.; Motta, T.; Natali, D.; Sampietro, M.; Campione, M. Fluorenone-thiophene derivative for organic field effect transistors: A combined structural, morphological and electrical study. Thin Solid Films 2005, 492, 212-220. [CrossRef]

34. Ekbote, A.; Jadhav, T.; Misra, R. T-Shaped donor-acceptor-donor type tetraphenylethylene substituted quinoxaline derivatives: Aggregation-induced emission and mechanochromism. New J. Chem. 2017, 41, 9346-9353. [CrossRef]

35. Grabowski, Z.R.; Rotkiewicz, K.; Rettig, W. Structural changes accompanying intramolecular electron transfer: Focus on twisted intramolecular charge-transfer states and structures. Chem. Rev. 2003, 103, 3899-4032. [CrossRef] 
36. Kanibolotsky, A.L.; Forgie, J.C.; McEntee, G.J.; Talpur, M.M.; Skabara, P.J.; Westgate, T.D.; McDouall, J.J.; Auinger, M.; Coles, S.J.; Hursthouse, M.B. Controlling the conformational changes in donor-acceptor [4]-dendralenes through intramolecular charge-transfer processes. Chemistry 2009, 15, 11581-11593. [CrossRef]

37. Soni, J.N.; Soman, S.S. Synthesis and antimicrobial evaluation of amide derivatives of benzodifuran-2-carboxylic acid. Eur. J. Med. Chem. 2014, 75, 77-81. [CrossRef]

38. Xie, F.; Zhu, H.; Zhang, H.; Lang, Q.; Tang, L.; Huang, Q.; Yu, L. In vitro and in vivo characterization of a benzofuran derivative, a potential anticancer agent, as a novel Aurora B kinase inhibitor. Eur. J. Med. Chem. 2015, 89, 310-319. [CrossRef]

39. Roviello, G.N.; Roviello, V.; Musumeci, D.; Pedone, C. Synthesis of a novel benzodifuran derivative and its molecular recognition of poly rA RNA. Biol. Chem. 2013, 394, 1235-1239. [CrossRef]

40. Carella, A.; Roviello, V.; Iannitti, R.; Palumbo, R.; La Manna, S.; Marasco, D.; Trifuoggi, M.; Diana, R.; Roviello, G.N. Evaluating the biological properties of synthetic 4-nitrophenyl functionalized benzofuran derivatives with telomeric DNA binding and antiproliferative activities. Int. J. Biol. Macromol. 2019, 121, 77-88. [CrossRef]

41. Shariat, M.; Abdollahi, S. Synthesis of benzoxazinone derivatives: A new route to 2 (N phthaloylmethyl)4H-3,1-benzoxazin-4-one. Molecules 2004, 9, 705-712. [CrossRef]

42. Papadopoulos, E.P.; Torres, C.D. A Simple Preparation of 2-Aryl-4H-3,1-benzoxazin-4-ones. Heterocycles 1982, 19, 1039. [CrossRef]

43. Caruso, U.; Panunzi, B.; Roviello, G.N.; Roviello, G.; Tingoli, M.; Tuzi, A. Synthesis, structure and reactivity of amino-benzodifurane derivatives. C. R. Chim. 2009, 12, 622-634. [CrossRef]

44. Beagley, B.; Flowers, W.T.; Hafees, A.; Pritchard, R.G. p- and o-Bis(N,N-diacetylamino)benzene. Acta Crystallogr. Sect. C Cryst. Struct. Commun. 1987, 43, 1971-1973. [CrossRef]

45. Diana, R.; Panunzi, B.; Marrafino, F.; Piotto, S.; Caruso, U. Novel Dicyano-Phenylenevinylene Fluorophores for Low-Doped Layers: A Highly Emissive Material for Red OLEDs. Polymers 2019, 11, 1751. [CrossRef]

46. Panunzi, B.; Concilio, S.; Diana, R.; Shikler, R.; Nabha, S.; Piotto, S.; Sessa, L.; Tuzi, A.; Caruso, U. Photophysical Properties of Luminescent Zinc(II)-Pyridinyloxadiazole Complexes and their Glassy Self-Assembly Networks. Eur. J. Inorg. Chem. 2018, 2018, 2709-2716. [CrossRef]

47. Borbone, F.; Caruso, U.; Palma, S.D.; Fusco, S.; Nabha, S.; Panunzi, B.; Shikler, R. High solid state photoluminescence quantum yields and effective color tuning in polyvinylpyridine based zinc(II) metallopolymers. Macromol. Chem. Phys. 2015, 216, 1516-1522. [CrossRef]

48. Obushak, M.D.; Martyak, R.L.; Matiychuk, V.S. Synthesis of heterocycles on the basis of arylation products of unsaturated compounds. Part 9. Dialkyl 2,6-diamino-4-arylfuro[2 $\left.2^{\prime}, 3^{\prime}: 4,5\right]$ benzo[b]furan-3,7-dicarboxylates from 2-aryl-1,4-benzoquinones and cyanoacetic esters. Pol. J. Chem. 2002, 76, 1419-1424. [CrossRef]

49. Kabsch, W. Integration, scaling, space-group assignment and post-refinement. Acta Crystallogr. Sect. D Biol. Crystallogr. 2010, 66, 133-144. [CrossRef]

50. Evans, P.R. An introduction to data reduction: Space-group determination, scaling and intensity statistics. Acta Crystallogr. Sect. D Biol. Crystallogr. 2011, 67, 282-292. [CrossRef]

51. Burla, M.C.; Carrozzini, B.; Cascarano, G.L.; Giacovazzo, C.; Polidori, G. Solving proteins at non-atomic resolution by direct methods: Update. J. Appl. Crystallogr. 2017, 50, 1048-1055. [CrossRef]

52. Sheldrick, G.M. Crystal structure refinement with SHELXL. Acta Crystallogr. Sect. C Struct. Chem. 2015, 71, 3-8. [CrossRef] [PubMed]

53. Farrugia, L.J. WinGXandORTEP for Windows: An update. J. Appl. Crystallogr. 2012, 45, 849-854. [CrossRef]

54. Müller, P.; Herbst-Irmer, R.; Spek, A.L.; Schneider, T.R. Crystal Structure Refinement: A Crystallographer's Guide to SHELXL; Oxford University Press: Oxford, UK, 2006. [CrossRef]

55. Macrae, C.F.; Sovago, I.; Cottrell, S.J.; Galek, P.T.A.; McCabe, P.; Pidcock, E.; Platings, M.; Shields, G.P.; Stevens, J.S.; Towler, M.; et al. Mercury 4.0: From visualization to analysis, design and prediction. J. Appl. Cryst. 2020, 53, 226-235. [CrossRef] [PubMed]

56. Felouat, A.; D'Aleo, A.; Charaf-Eddin, A.; Jacquemin, D.; Le Guennic, B.; Kim, E.; Lee, K.J.; Woo, J.H.; Ribierre, J.C.; Wu, J.W.; et al. Tuning the Direction of Intramolecular Charge Transfer and the Nature of the Fluorescent State in a T-Shaped Molecular Dyad. J. Phys. Chem. A 2015, 119, 6283-6295. [CrossRef] 
57. Diana, R.; Panunzi, B.; Shikler, R.; Nabha, S.; Caruso, U. A symmetrical azo-based fluorophore and the derived salen multipurpose framework for emissive layers. Inorg. Chem. Commun. 2019, 104, 186-189. [CrossRef]

58. Diana, R.; Panunzi, B.; Shikler, R.; Nabha, S.; Caruso, U. Highly efficient dicyano-phenylenevinylene fluorophore as polymer dopant or zinc-driven self-assembling building block. Inorg. Chem. Commun. 2019, 104, 145-149. [CrossRef]

59. Panunzi, B.; Borbone, F.; Capobianco, A.; Concilio, S.; Diana, R.; Peluso, A.; Piotto, S.; Tuzi, A.; Velardo, A.; Caruso, U. Synthesis, spectroscopic properties and DFT calculations of a novel multipolar azo dye and its zinc(II) complex. Inorg. Chem. Commun. 2017, 84, 103-108. [CrossRef]

60. Mishra, V.R.; Ghanavatkar, C.W.; Sekar, N. ESIPT clubbed azo dyes as deep red emitting fluorescent molecular rotors: Photophysical properties, pH study, viscosity sensitivity, and DFT studies. J. Lumin. 2019, 215, 116689. [CrossRef]

61. Warde, U.; Sekar, N. NLOphoric mono-azo dyes with negative solvatochromism and in-built ESIPT unit from ethyl 1,3-dihydroxy-2-naphthoate: Estimation of excited state dipole moment and pH study. Dyes Pigment. 2017, 137, 384-394. [CrossRef]

62. Chen, W.; Wright, B.D.; Pang, Y. Rational design of a NIR-emitting Pd(II) sensor via oxidative cyclization to form a benzoxazole ring. Chem. Commun. 2012, 48, 3824-3826. [CrossRef] [PubMed]

63. Panunzi, B.; Diana, R.; Concilio, S.; Sessa, L.; Shikler, R.; Nabha, S.; Tuzi, A.; Caruso, U.; Piotto, S. Solid-state highly efficient dr mono and poly-dicyano-phenylenevinylene fluorophores. Molecules 2018, 23, 1505. [CrossRef] [PubMed]

64. Rauf, M.A.; Hisaindee, S.; Saleh, N. Spectroscopic studies of keto-enol tautomeric equilibrium of azo dyes. RSC Adv. 2015, 5, 18097-18110. [CrossRef]

65. Satam, M.A.; Raut, R.K.; Sekar, N. Fluorescent azo disperse dyes from 3-(1,3-benzothiazol-2-yl)naphthalen-2-ol and comparison with 2-naphthol analogs. Dyes Pigments 2013, 96, 92-103. [CrossRef]

66. Borbone, F.; Caruso, U.; Concilio, S.; Nabha, S.; Piotto, S.; Shikler, R.; Tuzi, A.; Panunzi, B. From cadmium(II)-aroylhydrazone complexes to metallopolymers with enhanced photoluminescence. A structural and DFT study. Inorg. Chim. Acta 2017, 458, 129-137. [CrossRef]

67. Zhou, Z.; Li, W.; Hao, X.; Redshaw, C.; Chen, L.; Sun, W.-H. 6-Benzhydryl-4-methyl-2-(1H-benzoimidazol-2yl)phenol ligands and their zinc complexes: Syntheses, characterization and photoluminescence behavior. Inorg. Chim. Acta 2012, 392, 345-353. [CrossRef]

68. Panunzi, B.; Diana, R.; Caruso, U. A Highly Efficient White Luminescent Zinc (II) Based Metallopolymer by RGB Approach. Polymers 2019, 11, 1712. [CrossRef]

69. Roviello, A.; Borbone, F.; Carella, A.; Diana, R.; Roviello, G.; Panunzi, B.; Ambrosio, A.; Maddalena, P. High quantum yield photoluminescence of new polyamides containing oligo-PPV amino derivatives and related oligomers. J. Polym. Sci. Part. A Polym. Chem. 2009, 47, 2677-2689. [CrossRef]

70. Sk, B.; Khodia, S.; Patra, A. T and V-shaped donor-acceptor-donor molecules involving pyridoquinoxaline: large Stokes shift, environment-sensitive tunable emission and temperature-induced fluorochromism. Chem. Commun. 2018, 54, 1786-1789. [CrossRef]

71. Feng, S.; Gong, S.; Feng, G. Aggregation-induced emission and solid fluorescence of fluorescein derivatives. Chem. Commun. 2020, 56, 2511-2513. [CrossRef]

72. Salimimarand, M.; La, D.D.; Kobaisi, M.A.; Bhosale, S.V. Flower-like superstructures of AIE-active tetraphenylethylene through solvophobic controlled self-assembly. Sci. Rep. 2017, 7, 42898. [CrossRef] [PubMed]

73. Salimimarand, M.; La, D.; Bhosale, S.; Jones, L.; Bhosale, S. Influence of Odd and Even Alkyl Chains on Supramolecular Nanoarchitecture via Self-Assembly of Tetraphenylethylene-Based AIEgens. Appl. Sci. 2017, 7, 1119. [CrossRef]

74. Lee, C.S.; Park, J.T.; Kim, J.H. Structural color-tunable mesoporous bragg stack layers based on graft copolymer self-assembly for high-efficiency solid-state dye-sensitized solar cells. J. Power Sources 2016, 324, 637-645. [CrossRef]

(C) 2020 by the authors. Licensee MDPI, Basel, Switzerland. This article is an open access article distributed under the terms and conditions of the Creative Commons Attribution (CC BY) license (http://creativecommons.org/licenses/by/4.0/). 